\title{
THE TREATMENT OF URAEMIA WITH SPECIAL REFERENCE TO ACUTE RENAL FAILURE
}

\author{
By A. M. Joekes, M.A., B.M. \\ Department of Medicine, Post Graduate Medical School of London
}

The diagnosis of uraemia is often considered synonymous with a hopeless prognosis, or, at best, a condition from which a patient may recover but on which treatment has no specific effect. This paper attempts to set out a rational system of treatment for uraemia. The clinical picture, aetiology of the renal failure, diagnosis and prognosis are briefly considered before treatment is discussed.

Fishberg' has defined uraemia as ' the symptomcomplex resulting from renal insufficiency and accompanying the retention of urinary constituents in the organism.' It should not be forgotten that water is the most important urinary constituent, and many of the symptoms of oliguric uraemia result from its retention.

\section{Glinical Picture}

To await a clinical condition which allows of a confident bedside diagnosis of uraemia is to court disaster. The classical textbook picture would leave little room for doubt. A pale, drowsy or comatose patient with slightly yellowish tinge to his skin, showing generalized oedema, hiccoughing, the breath smelling uriniferous, the tongue dry and brown, involuntary twitchings of the limbs, positive Chvostek and Trousseau signs, possibly a bleeding tendency or generalized convulsions will complete an unmistakable clinical picture. In practice, the clinical condition of a uraemic patient is determined largely by the foregoing treatment, probably most of all on the maintenance or otherwise of the fluid balance. If ideally treated, a patient with a blood urea of $300 \mathrm{mgm}$. per cent. or more may present with a clean moist tongue, normal mental faculties, no oedema and, in short, with no abnormal physical signs.

So favourable a clinical picture is not likely to occur in the absence of very careful treatment; there will almost certainly be an acidosis, with an alkali reserve below 40 vols. per cent. (resulting in increased depth of respiration) and evidence of cardiac failure as judged by a raised venous pressure, although there may be little or no oedema unless fluid intake has been forced. Nevertheless, such a picture does not call to mind the uraemic syndrome as generally described and, unless the reduced urinary output is taken into account, the diagnosis will be overlooked. Indeed, the clinical picture in uraemia should be used more as a guide in management, rather than as a means of diagnostic labelling ; recognition must largely depend upon the clinical history.

\section{Diagnosis}

It is impossible to discuss the diagnosis of uraemia without stressing continually the importance of watching the urine output in any condition that may be complicated by renal failure. Not only must the volume passed in the 24 hours be taken into account but, especially in the presence of existing renal disease, the urea content be borne in mind.

Some classification of the cause of uraemia is useful in the approach to a case with renal failure, and a table is given based on Fishberg's ${ }^{1}$ three main groups. No attempt is made to give a comprehensive list but it may be useful as including the causes of renal failure most likely to be met with in practice.

\section{Prerenal.}

\section{Postrenal.}

I. Stone.

2. Prostatic obstruction.

3. Obstruction of ureters by carcinoma of the cervix.

4. Obstruction of the ureters by uterine prolapse.

Renal (Chronic).

I. Glomerular nephritis.

2. Pyelonephritis.

3. Nephrosclerosis (benign and malignant).

4. Polycystic kidneys.

5. Amyloid kidneys

6. Renal tuberculosis.

7. Renal calcinosis.

Renal (Acute).

I. Glomerular nephritis.

*2. Chemical poisons. Mercury. Carbon tetrachloride.

*3. Sulphonamides.
(a) Blockage
(b) Sensitivity. 
*4. Pigment nephrosis.

(a) Mismatched transfusion.

(b) Crush syndrome.

(c) Haemolytic infections.

(d) Severe burns with haemolysis.

(e) Ischaemic muscle necrosis.

(f) Blackwater fever.

*5. Shock kidney.

6. Cortical necrosis.

- Lower nephron nephroses (Lucke ${ }^{38}$.)

\section{Prerenal}

The group of prerenal causes of uraemia is not further subdivided owing to its complexity. Renal failure due to causes outside the kidney are typically seen after severe haemetemesis, in the crisis of Addison's disease, and after continued vomiting or diarrhoea. The main factors resulting in the renal failure would seem to be a fall in blood pressure, loss of water and loss of electrolytes. The importance of these various factors is, however, far from clear at present, and there may be others not yet appreciated. If the replacement of blood loss and the correction of dehydration or electrolyte disturbance in the presence of uraemia does not improve renal function, it must be assumed that there is a true renal cause for the uraemia, which may have been precipitated by a period of hypotension (shock kidney).

Acidosis is the result rather than the cause of renal failure. Whether alkalosis in itself, apart from the accompanying dehydration and reduced plasma chlorides, reduces renal function is not certainly established.

The mechanism of the anuria of the 'hepatorenal' syndrome is not known.

\section{Postrenal}

Consideration of the postrenal group should prevent the oversight of obstruction of the urogenital tract, as by stones, by prostatic or urethral stricture obstruction in the male and, more easily forgotten, ureteral blockage either by carcinoma of the cervix or due to prolapse of the uterus in the female. Any such obstruction may be accompanied by urinary infection and, indeed, the latter in the presence of oliguria should lead one to suspect an obstruction. It should be remembered that albumen and white cells in the urine are the rule in oliguria and do not in themselves denote infection. If urinary infection is present without evidence of obstruction and cannot be laid at the door of repeated instrumentation, previously existing pyelonephritis, tuberculosis or polycystic kidneys should re considered.

The diagnosis of postrenal or obstructive uraemia must not be missed as surgical relief of the block or pyelostomy should be performed at the earliest opportunity.

\section{Renal}

Renal failure due to a primary disturbance within the kidney itself may conveniently be $\stackrel{\AA}{\varrho}$ grouped into two main categories, old-standing $\hookrightarrow$ renal disease in which some added insult has re- $\overrightarrow{\vec{B}}$ duced effective renal function below the necessary minimum, and acute renal disease or catastrophe $\frac{C}{0}$ occurring in previously healthy kidneys. It may $\frac{\bar{\omega}}{\bar{\omega}}$ be exceedingly difficult to differentiate between $\vec{\mathbb{}}$ these two groups clinically ; and it is usually the $\varrho$ clinical history rather than the examination which o allows one to make a tentative diagnosis. Evidence $\overrightarrow{0}$ of previously existing hypertension should lead one to suspect old renal damage and sometimes the urinary sediment may be of assistance.

The differential diagnosis of the causes of acute renal failure must, again, depend largely on obtaining an accurate history, although a few $\mathrm{N}$ clinical points may be helpful. Jaundice or a $\mathbb{\infty}_{\infty}$ raised serum bilirubin may be found in the first day or so of the pigment nephroses. A raised

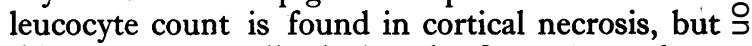
this occurs normally during the first two or three $\vec{T}$ days post-partum, and, of course, if there is sepsis. $\frac{1}{0}$ $A$ raised blood pressure may be suggestive of $\frac{0}{C}$ glomerular nephritis, but can also occur with lower nephron nephroses.

It is extremely common to have a true ren⿳⺈冂大 uraemia complicated by vomiting, resulting in the loss of water and salt, the patient presenting de्s hydrated and with a low blood pressure, so that when first seen both a prerenal and a renal cause $\frac{\partial}{0}$ for the condition exist. In such a case it may be impossible to diagnose the presence of an intra- $\stackrel{\mathbb{Q}}{\mathbb{2}}$ renal cause until it is found that correcting the $\overrightarrow{\overrightarrow{\vec{P}}}$ extrarenal cause does not restore kidney function. $\frac{9}{3}$ Such an instance is typically seen in a case with $\vec{T}$ chronic dyspepsia, taking alkalis over many우 months, who presents dehydrated, alkalotic and with a raised blood urea and lowered plasma 3 . chloride; the intravenous administration of $\dot{\sigma}$ normal saline will in many cases restore a renal 3 . function adequate to correct the alkalosis and re- $\delta$ duce the urea to normal. In a proportion of such $₹$ cases the administration of intravenous saline does 0 not allow the kidney to restore to normal the blood $>$ chemistry, and it can then be assumed that there is present severe chronic renal damage.

Presented with a case of renal failure which has $\stackrel{N}{\circ}$ persisted for several days and in which con- $\mathbb{O}$ siderable nitrogen retention already exists, the primary problem should be treatment which may be urgent, and unless successful, detailed diagnosis 0

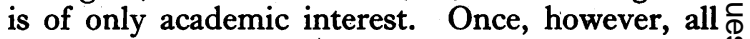
aspects of treatment that will be discussed have $\stackrel{\oplus}{+}$ been attended to, then every effort should be made $T$ to make as precise a diagnosis as possible. This is of importance in relation to prognosis and it is 
only by so doing that one may hope to unravel some of the obscure oligurias. Unfortunately the modern techniques for investigating renal dynamics tell one little more than the degree of renal damage and nothing about the aetiology, nor are they helpful in prognosis, except in so far as they allow one to follow the recovery of function in greater detail than a simple urea clearance test. In the presence of anuria no renal function tests can, of course, be applied ; indeed there is no renal function. It is therefore not known whether there is some glomerular filtration with quantitative return of this filtrate into the blood stream, or whether there is complete absence of filtrate formation.

\section{Pregnancy Anurias}

The anurias related to pregnancy constitute the largest group met in practice. O'Sullivan and Spitzer $^{2}$ have reviewed the literature of renal failure complicating abortion. With septic abortion, the kidney lesion is usually a pigment nephrosis due to infection with haemolytic organisms. In the case of non-septic abortion, the lesion may be either a pigment nephrosis or a bilateral cortical necrosis. Post-partum complications are related most commonly to haemorrhage or toxaemia. As after any severe blood loss, postpartum haemorrhage may be followed by oliguria secondary to the fall in blood pressure and blood volume. Concealed accidental (ante-partum) haemorrhage is usually preceded by the signs of toxaemia even if only for a few days, and if complicated by renal failure the lesion in fatal cases is found to be bilateral cortical necrosis. Delivery after toxaemia without placental separation has also been recorded as complicated by cortical necrosis.

\section{Prognosis}

Severe renal failure occurring in the presence of chronic renal damage can be an extremely difficult prognostic problem. An acute episode of glomerular nephritis complicating chronic nephritis, whether severe oliguria occurs or not, may settle, leaving the patient with a further reduction in functioning kidney tissue. The ultimate prognosis must depend largely on the residual renal function and the severity of the cardiovascular strain. With other forms of chronic renal damage an episode of acute failure is usually brought about by some prerenal factor or a superimposed urinary tract infection. If the immediate cause of the aggravation can be treated, the prognosis is that of the underlying renal condition.

If anuria occurs in malignant hypertension, this must be considered as a terminal event.

If with chronic renal damage severe nitrogen retention occurs the prognosis depends largely on the ability of the kidneys to excrete an adequate volume of urine, i.e. 2 litres or more in the 24 hours. If, despite sufficient water and salt administration, the urine volume cannot be increased enough to compensate for the poor concentrating power of the kidneys the prognosis is hopeless.

Of the acute causes of uraemia only in the case of bilateral cortical necrosis is there no convincing evidence that the kidneys will recover if the patient survives sufficiently long, something of the order of three weeks in the most severe cases. Duff and More $^{3}$ reviewed the reported cases of cortical necrosis up to I94I; of 77,48 had complicated pregnancy. Such a review is necessarily based on post-mortem evidence, and therefore fatal cases ; Gibberd $^{4}$ and others ${ }^{5} 6$ ? have claimed that the diagnosis of bilateral cortical necrosis can be confidently made on occasions, and he described two cases so diagnosed with post-partum anuria who both recovered. Acute glomerular nephritis only falls into this group when severe oliguria or anuria persists for more than two or three days. Such an oliguric episode is not necessarily an indication of a severe renal damage. If the patient can be tided over the oliguric episode the prognosis is probably the same as for an attack in which severe oliguria does not occur, in other words, an 85 per cent. chance of complete recovery is to be expected

It should therefore be assumed that in any case of anuria or oliguria if the patient can be kept alive for three weeks, kidney function will have recovered sufficiently to support life. The majority of lower nephron nephroses will have started a diuresis in 14 days. This will not be true for, at least, most cases of cortical necrosis. As the latter diagnosis cannot be proved in life, treatment should be as active as for any acute renal failure; it is moreover possible that some degree of recovery might take place if life be prolonged beyond 12 days, within which time the great majority of the recorded cases have died. Any case of lower nephron nephrosis, that is any condition falling into subdivisions $2,3,4$ and 5 of the causes of acute renal failure, which has survived the acute episode will show a slow improvement of renal function reaching normal or slightly below normal values in anything up to nine months.

\section{Treatment}

As the first step in treatment the possibility of postrenal obstruction must be considered: If such an obstruction exists and cannot be relieved, nephrostomy should be performed immediately. If sulphonamides have been administered up to the onset of oliguria and might be a cause for obstruction, ureteric catheters should be passed 
and the renal pelves -washed out. Obviously sulphonamides must not be administered in the presence of oliguria.

Of the renal causes of uraemia there are two main groups of patients : one in which anuria or oliguria persists for some days despite treatment so that insignificant amounts of breakdown products are excreted ; the other in which the concentrating power of the kidneys has become grossly impaired but in which a large urine volume can be maintained with correct management. There is no essential difference in the treatment of the two groups. In the presence of anuria the retention of potassium plays an important part, whereas the ability to excrete potassium is usually maintained while the kidney can excrete water.

\section{Emergency Treatment}

Apart from the replacement of blood loss after haemorrhage and the correction of dehydration and electrolyte depletion, there are only two groups of kidney catastrophe in which immediate treatment may be of decisive importance.

In the pigment nephroses, the renal lesion is thought to be dependent on the precipitation of haemoglobin or myohaemoglobin in the tubules. This precipitation probably varies with the concentration of the pigment in the affected tubules, with the change in $\mathrm{pH}$ of the filtrate to acid, and possibly with the concentration of sodium chloride. Clinically, as judged by the onset of oliguria, the renal damage is complete within 24 and possibly within 12 hours. It would seem rational therefore to attempt to dilute the urine maximally in the first 12 hours after the transfusion or injury and to administer alkalis sufficient to render the urine alkaline. Bywaters ${ }^{8}$ advised for the crush syndrome cases that, as an immediate first aid measure, one pint of fluid with one teaspoonful of bicarbonate be given by mouth every hour for the first 12 hours, or, if the patient is in hospital, intravenous isotonic ( 1.87 per cent.) sodium lactate in the same quantities. It should be added, however, that excess of total fluid intake over output should not at any time be allowed to be more than 1,500 cc. ( $2 \frac{1}{2}$ pints), unless an existing dehydration has to be corrected. Very good experimental evidence is offered for the use of isotonic (4.3 per cent.) sodium sulphate in the anuria produced by haemoglobinaemia secondary to severe burns $^{9}$. If this work is accepted as valid, sodium sulphate should be used in place of sodium lactate. If in the first 24 hours a successful diuresis is obtained, the fluid intake should be such as to maintain a daily urine volume of about 3 litres ; this will require 4 litres ( 7 pints) intake. To keep the urine alkaline about $2 \mathrm{gm}$. (30 gr.) of $\mathrm{bi}$ - carbonate are required in the day. It must be stressed that to attempt to force a diuresis by $\frac{\varrho}{3}$ giving large quantities of fluid after the first 12 क hours is exceedingly dangerous unless the urine $\stackrel{\varrho}{\iota}$ output keeps pace with the fluid intake. Any patient with lower nephron nephrosis, particularly those due to chemical poisons, may have a diuresis 0 in the first 24 hours and then become anuric.

The other group of renal catastrophe which $\frac{\bar{D}}{\bar{D}}$ may benefit by emergency treatment is acute $\stackrel{\mathbb{Q}}{2}$ mercury poisoning. If adequate treatment with क BAL is instituted within three hours of the $\vec{\circ}$ administration of the mercury, the prognosis is very much improved ${ }^{10}$. Of the total course of $\vec{\omega}$ BAL, up to 2 gm., 600 to $75^{\circ} \mathrm{mgm}$. should be 'given in the first 12 hours after the event.

\section{General Treatment}

Treatment of a uraemic patient can be con- $\infty_{0}^{\circ}$ sidered under several main headings :-

I. Diet.

2. Water balance.

3. Correction and maintenance of electrolyte pattern.

4. Prevention or treatment of intercurrent infection.

5. Blood, peritoneal and intestinal dialysis.

6. Correction of anaemia.

\section{Diet}

The symptom complex of uraemia is probably $\stackrel{\mathbb{Q}}{\mathbb{2}}$ dependent on the retention in the body of many $\overrightarrow{\overrightarrow{0}}$ substances normally excreted in the urine, $\frac{0}{3}$ aggravated by disturbances in the electrolyte $\supset$ pattern and the acid-base balance. Endogenous or exogenous protein breakdown is almost entirely responsible for the accumulation of the toxic sub- 3 . stances. A starving man will katabolize about $\overline{0}$ $50 \mathrm{gm}$. of endogenous protein a day, whereas, if given no protein but an adequate calorie intake in $\delta$ the form of carbohydrate and fats, he will katabolize less than $2 \mathrm{gm}$. of nitrogen or about $12 \mathrm{gm}$. 옥 protein. In other words the normal daily urea $D$ excretion of about $20 \mathrm{~g}$. can be reduced by a을 high-calorie, low-protein diet to $5 \mathrm{~g}$. per day. N Expressed as the theoretical daily rise in blood urea level in an anuric patient, this would be $\tilde{O}$ equivalent to a ro mgm. per cent. as opposed to $\tilde{\omega}^{-}$ $40 \mathrm{mgm}$. per cent. rise.

Kempner $^{11}$ and Borst ${ }^{1213}$ have stressed the $\mathscr{C}$ importance of giving adequate-calorie, low-protein diets to uraemic patients. Below is given a list of the protein content of some of the main foods (extracted from Borst) :- 


\begin{tabular}{|c|c|c|c|c|c|}
\hline Alcohol .. & $\ldots$ & & $\begin{array}{c}\text { Gm. } \\
\text { protein } \\
\text { per Ioo } \\
\text { gm. } \\
0\end{array}$ & $\begin{array}{c}\text { Calories } \\
\text { per I00 } \\
\text { gm. } \\
700\end{array}$ & $\begin{array}{c}\text { Gm. } \\
\text { protein } \\
\text { per } 2,000 \\
\text { cals. } \\
0\end{array}$ \\
\hline Sugar ... & $\ddot{0}$ & $\ddot{\cdots}$ & 0 & 400 & 0 \\
\hline $\begin{array}{l}\text { Butter . } \\
\text { Cornflour }\end{array}$ & . & .. & 0.44 & 800 & I. I \\
\hline $\left.\begin{array}{l}\text { Tapioca } \\
\text { Sago }\end{array}\right\}$ & .. & .. & 0.5 & 350 & 2.75 \\
\hline Fruit $\ldots$ & .. & $\therefore$ & $0.25^{-1} .0$ & $30-100$ & 12 \\
\hline Cream (40 per & cent. & fat) & 2.4 & 400 & 12 \\
\hline $\begin{array}{l}\text { Potato } \\
\text { Rice (raw) }\end{array}$ & $\cdots$ & $\cdots$ & $\begin{array}{l}1.44 \\
6.8\end{array}$ & $\begin{array}{r}80 \\
360\end{array}$ & $\begin{array}{l}36 \\
38\end{array}$ \\
\hline Bread (old) & $\ldots$ & $\cdots$ & 9.1 & 250 & 73 \\
\hline Milk .. & $\ldots$ & $\ldots$ & 3.25 & 545 & 125 \\
\hline Egg $(2=100$ & gm ) & . & I I .9 & 170 & 200 \\
\hline Greens & . . & .. & $1.0-5.0$ & $10-50$ & 200 \\
\hline Meat (lean) & . & .. & 22.0 & 125 & 350 \\
\hline
\end{tabular}

It will be seen that butter and sugar must form the main basis of any diet, with cornflour, tapioca, sago and fruit as the vehicles for making something palatable. Rice, although having a fairly high protein content, is extremely useful owing to its high calorie value and can be used as the mainstay of one hot meal in the day. Salt must not be given as a rule while the patient is anuric, which is a further difficulty in making the diet sufficiently palatable. In practice, in this country, it has been found impossible to get patients to take a calorie intake of 2,000 per day, which is aimed at, the average intake with a co-operative patient working out at 1,000 calories.

In the presence of anuria the intake of potassium must be kept to a minimum. Milk contains a high potassium content; not more than $500 \mathrm{gm}$. of fruit should be given daily. Synthetic fruit juices may contain more than $10 \mathrm{mgm}$. per cent. of potassium and must not be given ${ }^{14}$.

Recently it has been found that an adequate calorie intake can be assured by feeding by stomach tube a mixture of fat and sugar in water as a continuous nasal drip ${ }^{15}{ }^{16}$. This method also allows the fluid and salt intake to be very accurately controlled.

\section{Water Balance}

In reviewing treatment of 33 cases of urinary suppression Lattimer ${ }^{17}$ found that of those receiving less than 2,000 cc. total fluids in the 24 hours none died, whereas of those in whom 3,500 cc. or more was given 75 per cent. died. He sums up his view by stating : " the body is not analogous to a tank into which water can be forced until it finally bursts out through the kidneys.'

In all probability most uraemic deaths are due to cardiac failure, in which overloading with water with consequent pulmonary oedema is the most important precipitating factor ${ }^{36}$ 37. Electrolyte disturbances, in particular retention of potassium, may seriously affect the heart action.
If no water is lost from the body through the kidneys, the only losses are by way of the lungs and skin, and in the faeces and vomit. The expected water loss by these routes, in the absence of vomiting or diarrhoea, totals about one litre a day and this volume of water will be required by an anuric patient to maintain fluid balance. Kugel ${ }^{18}$ suggested $700 \mathrm{cc}$. of normal saline as the basic daily requirement and stresses the possible importance of endogenous water produced by metabolism and cell breakdown. The administration of salt to anuric patients, $700 \mathrm{cc}$. normal saline giving 6.3 gm., cannot, however, be accepted unless dehydration is present. The route of administration is not important but the total amount of fluid administered by mouth, intravenously or by rectum, must be taken into account. Whole blood given intravenously should not be included as fluid intake. From the onset of anuria a patient should be given a total fluid intake in 24 hours of not less than $700 \mathrm{cc}$. and not more than $1,500 c c$. If vomiting or diarrhoea are present the amount of fluid thus lost should be given in addition to the above, and the loss of sodium chloride will have to be replaced as well. In the case of vomit, half the volume of fluid lost should be given as normal saline.

When once a diuresis starts, or in cases already passing urine, the fluid intake should total $1,500 \mathrm{cc}$. plus the volume of the previous 24 hour urine output. It is essential that accurate fluid intakeoutput charts are kept whenever a case of renal failure is treated, and these must be continued until the blood urea is reduced to normal. Although a diuresis has started after a period of anuria this does not mean that the patient is out of danger, and it is still easily possible to overload with water or, if insufficient fluid is administered, to prevent the kidneys from excreting sufficient amounts of katabolic products. Following a period of oliguria it is the rule for the kidneys to be unable to concentrate for some weeks. During the first week or so of diuresis the urine urea concentration will be about the same as in the blood, i.e. between 200 and $500 \mathrm{mgm}$. per cent., and it should be assumed that a litre of urine will contain less than $5 \mathrm{gm}$. of urea. It is therefore not surprising that the blood urea may continue to rise for some days after the start of a diuresis. This gives no cause for alarm, but illustrates the need for continuing extremely careful management until the patient's blood urea is normal.

Before discharging a patient who has had an episode of renal failure, the concentrating ability of the kidneys should be assessed. From the urea concentration in a 24-hour specimen of urine the required minimum daily urine volume on a given protein intake can be calculated :- 


\section{e.g. urine urea concentration $800 \mathrm{mgm}$. per cent. daily protein intake .. $40 \mathrm{gm}$.}

If it is assumed that I $\mathrm{gm}$. urea is equivalent to $3 \mathrm{gm}$. of protein, the minimum required 24 hour urine vol. $=\frac{40}{0.8 \times 3} \times 100 \mathrm{cc}$. $=1,670 \mathrm{cc}$.

These figures are of the order expected in either a recovering acute lesion or in a chronic lesion with enough function to avoid increasing nitrogen retention.

In such cases it is safer not to allow the volume of urine passed in the 24 hours to fall below a minimum of two litres. A Winchester bottle (2 litres) can be used for a patient to collect a 24-hour urine once or twice a week, and unless this is filled in 24 hours, the quantity must be considered insufficient, and the patient must take more fluids. Where the renal failure was the result of one of the 'catastrophes' in previously normal kidneys, it can be confidently expected that renal function will continue to improve until, between four and nine months after the event, almost normal function will have returned. The necessity of maintaining a large daily urine output may then only persist for some two months after the start of diuresis.

\section{Correction and Maintenance of Electrolyte Pattern}

Patients with gross renal failure, whatever the aetiology, usually present with a disturbance of the electrolyte pattern. In the group of renal catastrophes with oliguria it is common to find a reduction in the plasma chloride level, not necessarily explicable by loss in vomit, and the bicarbonate may also be low.

Despite a very low plasma chloride, patients may not present with clinical dehydration. With chronic renal insufficiency the bicarbonate is almost invariably low and the chloride level is more nearly related to the loss of chloride in vomit. In the latter group the kidney is probably able to excrete water and it is then possible to administer salt with water as a vehicle to correct a low plasma chloride level. But in the presence of anuria, the administration of salt is extremely difficult as one has at most $I, 500$ cc. per day in which to give it ; if more than half strength saline is given by mouth vomiting is likely. A low chloride level may well play an important part in maintaining a disturbance of renal dynamics, and a gross reduction in the presence of oliguria may be an indication for some form of dialysis with which it is possible to right an electrolyte imbalance without waterlogging the patient.
In those cases in which a large urine volume has to be maintained because of poor concentrating ability, it is most important to consider the loss of sodium chloride in the urine. Obviously least osmotic work is demanded of the kidneys if the concentration of sodium chloride is the same in $\stackrel{5}{7}$ the urine as in the plasma, i.e. of the order of $600 \mathrm{mgm}$. per $100 \mathrm{cc}$. If. the urine volume is $2,500 \mathrm{cc}$. in the day, this would represent a loss of $15 \mathrm{gm}$. of salt. In the presence of poor renal function the patient will be put on a low-protein diet to reduce the work in excreting urea, and the diet is unlikely to contain much salt. Added salt may therefore have to be given to cases with either chronic renal damage or, in the recovery stage of an acute failure ; the amount is most safely established by estimating the chloride content of a 24-hour specimen of urine. The extra salt administered can be either as tablets or in capsules, but should be given with meals to reduce the tendency to vomiting.

The reduction of the plasma bicarbonate may in itself not be of serious importance, but rather a reflection of the retention of acid radicles. Dialysis can correct a low bicarbonate value to normal, presumably removing retained acids at the same time. The presence of an acidosis, as judged by the bicarbonate level, is not sufficient indicatio for active intervention by dialysis. Whether as attempt to correct the acidosis by the administrae tion of alkalis is of value, as is particularly stressed by $\mathrm{Kirk}^{19}$ for acidosis of any origin, primarily renal or not, is still uncertain. There can, however, be no doubt that the maintenance of the fluid balance in oliguria is of far greater importance than the correction of an acidosis. Many patients survive after being severely acidotic during a period of anuria, few survive when once gross oedema has developed. It has yet to be shown that the administration of alkalis to the patient with chronic renal damage and acidosis is of greater benefit than the administration of salt.

Potassium retention can be of great significance in oliguria, and may be the main immediate cause for death in cardiac failure ${ }^{20}$. It is difficult to explain the very sudden death that may occur in an anuric patient with only a moderately raised blood urea value, e.g. $200 \mathrm{mgm}$. per cent., and as potassium intoxication, as seen in the electrocardiogram, is of grave prognostic significance, a further rise in serum potassium due to cell breakdown could conceivably cause cardiac arrest. The main electrocardiographic change is in the $T$ waves, best seen in Lead II and $\mathrm{V}_{3}$; the $\mathrm{T}$ wave becomes sharp and rises abruptly from the $\mathrm{S}-\mathrm{T}$ segment, which is usually isoelectric and occasionally depressed, although it may be terminally raised and slurred into the $T$ wave. Late changes 
described are widening of the QRS complex, and disappearance of the $P$ waves ${ }^{21}$.

Potassium retention is particularly likely to be of importance in cases of anuria related to pregnancy with an involuting uterus, or in patients with extensive sepsis. The avoidance of food and drinks containing much potassium has been mentioned in the section on diet.

Apart from the use of insulin combined with carbohydrate administration to attempt to deposit potassium in the tissues with glycogen ${ }^{22}$, dialysis is the only means of reducing a dangerous level of serum potassium.

A reduction of free calcium ions, or the accumulation of a substance counteracting their effect such as guanidine, may give rise to tetany and prolong cardiac systole as shown by a lengthened Q-T interval in the electrocardiogram. Calcium gluconate will abort tetanic attacks, although these may recur within a relatively short time.

An increase in plasma phosphate roughly parallels the urea retention, and, except for reducing the ionized calcium, is apparently not harmful. The rise parallels the nitrogen retention.

It is considered that no attempt should be made to right an electrolyte imbalance at the expense of upsetting the water balance. Potassium retention is the only absolute indication for active intervention with dialysis.

\section{Prevention or Treatment of Intercurrent Infection}

Any uraemic patient is extremely liable to infection, which would increase the katabolic processes in the body. It is therefore of the greatest importance to guard against the possibility of infection. Humphrey and AveryJones $^{14}$ advocated the routine use of preventive penicillin in acute renal failure, and found that an adequate blood level was maintained in the presence of anuria with a single dose of 45,000 units repeated every fifth day.

The treatment of an established infection must be vigorous. The drug of choice is penicillin and relatively enormous doses may be. safely given if an exceptionally high blood level is indicated for a partially resistant organism.

Sulphonamides must be avoided unless there is a good urine flow, preferably above two litres in the day.

\section{Blood, Peritoneal and Intestinal Dialysis}

Sweating and purging were the traditional methods of treating uraemia, but not only are insignificant amounts of urea removed by these routes, but the danger of causing serious water and electrolyte balance disturbances is very great.

The belief that any toxic effects of retained protein breakdown products can be lessened by a dilution effect, that is by increasing above normal the water content of the body, ignores the extreme danger of waterlogging an anuric patient.

In the last few years increasing attention has been given to the possibility of removing retained products by means of dialysing the patient's blood against a physiological saline solution. The semi-permeable membrane could either be the peritoneum or the gut, or the blood could be led through a Cellophane tube.

\section{Artificial Kidney}

Kolff $^{23} 24$ was the first to develop extracorporeal blood dialysis into a practical method. Blood flows outside the body through a cellophane membrane immersed in a bath containing a solution of sodium chloride, sodium bicarbonate, potassium chloride and glucose, the latter in sufficient concentration to compensate for the osmotic pressure of the plasma proteins. The patient is heparinized, blood flows from a cannula in a radial artery into a hundred foot length cellophane tube, which is wound in a spiral on a wooden lath drum. This drum is half immersed in a bath of 100 litres, and revolves so that the blood travels in a thin film along the cellophane tubing by the principle of an Archimedes screw, and is then returned into a vein by means of a pump.

Alwall ${ }^{25}$ and Gordon Murray and Delorme ${ }^{26}$ have independently developed blood dialysers for the treatment of uraemia similar in principle but different in detail from Kolff's.

Using the Kolff type of artificial kidney it is found that in a single passage through the Cellophane the urea content of a sample of blood can be reduced from over $400 \mathrm{mgm}$. per cent. to $40 \mathrm{mgm}$. per cent. or less. Similarly, the bicarbonate and chloride content can be brought to within normal limits whatever their values in the blood passed into the ' kidney.' Creatinine, uric acid and phenols are also removed by dialysis. Owing to a certain amount of haemolysis which always occurs with the dialysis, it is difficult to obtain figures on the removal of the potassium ion from th 2 plasma, but there can be no doubt that this is achieved.

Both Kolff and Alwall claim that generalized oedema can be reduced by dialysis, but where it is not possible to weigh these patients before and after without a weighing table, no convincing figures have been obtained in humans. Working with animals Alwall was able to reduce the body weight by $\mathrm{I}$ per cent. per hour ${ }^{27}$.

\section{Peritoneal Dialysis}

The use of the peritoneum as a semi-permeable membrane for the removal of toxins has long been 
considered. In 1934 Balasz and Rosenak used peritoneal lavage in the treatment of a case of anuria resulting from mercury poisoning ${ }^{28}$. Frank, Seligman and Fine $^{29}$ performed animal experiments with peritoneal lavage in induced uraemia, and went on to treat a patient with uraemia. Since then a large number of cases have been treated by peritoneal irrigation. In short, the method consists of running through the peritoneum, either continuously or intermittently, a fluid very similar to that described as used in the bath water for the artificial kidney. Blockage of the outflow tube, in the case of intermittent perfusion the same as the inflow tube; is one of the main technical difficulties with the danger of retention of excess fluid.

$\mathrm{Kop}^{30}$, using the technique for continuous peritoneal dialysis described by Kolff ${ }^{24}$, has dialysed 21 patients on 35 occasions. In only two was there any resulting infection of the peritoneum, and in neither was this severe enough to be the cause of death.

Apart from estimating blood urea and electrolyte levels before and after dialysis, it is more difficult to assess the effect of peritoneal than of blood dialysis, in which a sample of blood can be taken before and after passing through the cellophane tubing. With a flow speed of about 2 litres per hour through the peritoneum an original blood urea level of $300 \mathrm{mgm}$. per cent. might be brought down in ro hours perfusion to $200 \mathrm{mgm}$. per cent. Increased serum potassium levels can be reduced : in one case the level before dialysis was $56.6 \mathrm{mgm}$. per cent. and was brought down to $34.9 \mathrm{mgm}$. per cent. ${ }^{30}$. Other electrolyte disturbances are also righted.

\section{Intestinal Dialysis}

The intestine can be used as a semi-permeable membrane in several ways. A multilumen tube may be passed into the small intestine, a perfusing fluid is run in through one lumen high up in the gut, and is sucked out low down through an aperture just above the end of the tube ${ }^{31}$. Perfusing fluid may be run into the colon and collected through an appendicostomy opening ${ }^{24}$. For chronic renal insufficiency it has been suggested that a permanent double enterostomy with a loop of ileum could be used for intermittent irrigation ${ }^{32}$ 24. With all these methods of intestinal dialysis, the difficulty arises of preventing excess water and salt absorption from the gut, apart from the relatively poor rate of urea removal. It cannot be considered that intestinal dialysis has yet an established place in the treatment of uraemia.

\section{Replacement Transfusion}

It is obvious that replacement of a uraemic patient's blood by fresh donor blood will remove protein breakdown products. The latter are, $\frac{\mathbb{D}}{2}$ however, distributed throughout the extra-cellular water if not throughout the entire body water, and an exchange transfusion to be effective will require a very large volume of donor blood, of the order of 60 or more pints. This is impracticable only on the score of the difficulty of obtaining sufficient blood; this is the greater in view of the high proportion of anurias related to pregnancy and mismatched transfusions in which $R h$ negative blood may be imperative.

\section{Indications for Dialysis}

It may be accepted that extra-renal removal of protein breakdown products and the correction of electrolyte imbalances by some form of dialysis has a place in the management of acute renal $i$ failure. To define the indications for its use is $\mathbb{O}^{\circ}$ extremely difficult. While admitting that as a general index of the severity of uraemia the blood urea level is very useful, it must be emphasized that some patients may have the blood urea rising to over $500 \mathrm{mgm}$. per cent. and recover, while others die with a blood level of only $200 \mathrm{mgm}$. per cent. If it could be argued that there were no risks or disadvantages attached to the use of ang form of dialysis, the logical step would be te prevent the blood urea rising even over 200 mgmos per cent., and preventing any electrolyte imbalance occurring. Any uraemic patient is, however, very liable to infection, and interference must increase this risk. Borst has suggested, without any direct evidence, that both peritoneal and blood dialysis result in increased body protein breakdown ${ }^{13}$.

The oliguric patient in whom the management has been poor, will present with gross oedema, very acidotic, with low blood chlorides, raised venous pressure, pulmonary oedema and a high blood urea. Such patients can no longer with safety be treated expectantly, and dialysis should be performed in the hope that the clinical condition can be righted sufficiently for the more conservative methods then to be employed.

As previously stated, the presence of marked potassium intoxication as judged by the electrocardiogram is probably an absolute indication for dialysis, whatever the blood urea level.

The relative merits of peritoneal dialysis and the artificial kidney are not yet clear. Theoretically it is attractive to dialyse the blood direct by running it through a semi-permeable membrane, but this requires full heparinization of the patient, which in itself must carry a risk, however small. Possible $\mathbb{\complement}$ sudden changes in blood volume during dialysis ? with the Kolff artificial kidney have been considered an additional risk, particularly where most of the patients have some degree of heart failure ${ }^{33}$. 
Peritoneal dialysis is a somewhat simpler procedure, but the efficiency as judged by removal of urea per hour is less, and the danger of infecting the peritoneum is considerable, although Kop's results are very encouraging. Meteorism and abdominal pain are frequent complications of uraemia, and it is not always possible to perform peritoneal dialysis.

Whichever method of dialysis is chosen, it is an operation that can be undertaken only with the most careful technical detail and biochemical control. The possible dangers in either method are so great that dialysis may get into disrepute if performed without rigid controls.

\section{Correction of Anaemia}

Chronic renal disease with nitrogen retention is usually accompanied by moderately severe anaemia. The anaemia is normocytic and orthochromic, and is thought to be due to a depressant effect of some retained product on the bone marrow. As a part of routine treatment patients with chronic renal disease and anaemia should be given a transfusion of packed cells, with the usual care against overloading the heart, once every two to three months.

The acute renal failures are commonly associated with a rapidly developing anaemia down to a haemoglobin level of $5 \mathrm{gm}$. or even less. In many instances this severe anaemia is unexplained. Where haemolysis may be the immediate cause of renal failure, the transfusion of blood must only be done with every known precaution. Preferably packed cells should be used to lessen the likelihood of imposing further strain on the heart, if it is decided to transfuse during the period of oliguria. Whether the correction of the anaemia should be attempted while oliguria is still present is undecided. With the passing of the nitrogen retention the anaemia tends to right itself spontaneously.

\section{Renal Decapsulation and Splanchnic Block}

Large numbers of cases of oliguric uraemia have been treated by renal decapsulation ${ }^{34}{ }^{35}$ or some form of nerve block, most commonly a splanchnic block $^{2}$. These procedures are presumably based on the belief that the primary reason for the continued renal failure is a reduction in the renal blood flow, and that if this can be restored the kidney function will recover.

The results of these operations are extremely difficult to assess as they are usually only one of many forms of treatment used in the same patient. There are undoubtedly cases in whom a diuresis starts from the time of decapsulation or splanchnic block ; frequently these have been used only in the last resort at a time when a lower nephron nephrosis, i.e. either a toxic or pigment nephrosis, might be expected to be recovering some renal function. If any such case can be kept alive for I4 days from the onset of anuria a diuresis will probably have set in.

There are, however, many cases in which either splanchnic block or decapsulation have failed to produce a diuresis, and such negative results make it certain that no very specific effect can be claimed for these manoeuvres. It is not considered that there is any place for either in the treatment of acute renal failure.

\section{Diuretics}

There is no evidence that any diuretic has the least value in instigating a diuresis in a patient with anuria due to a renal cause. Their use in the first 24 hours of a pigment nephrosis is based on the maintenance of a diuresis rather than a specific effect on a damaged kidney.

\section{Conclusion}

From the point of view of treatment, renal failure is divided into two main groups. In the one group correct management will ensure a sufficient daily volume of urine to enable the kidneys to excrete an adequate quantity of protein breakdown products despite a poor concentrating power. The amount of protein in the diet is calculated from the quantity of urea that can be excreted in the 24 hours ; I gm. of urea may be taken as equivalent to $3 \mathrm{gm}$. of protein. To reduce the osmotic work by the kidneys or to replace salt loss by kidneys unable to conserve it, salt may have to be administered in excess of what is taken in the diet. This group consists of chronic renal damage and the recovery stage of the acute renal catastrophes. In the terminal stage of chronic renal failure the urine concentration will not only be poor, but it may be impossible to increase the urine volume above a litre or so, and unless a high calorie and minimal protein dięt is given, increasing nitrogen retention is inevitable.

The other group forms the main subject of this paper, and comprises acute renal failure with anuria or oliguria, whether this has arisen on an existing chronic renal damage or in previously healthy kidneys. Any oliguria due to an intrarenal cause lasting more than a few days, unless a terminal event in an old lesion, is probably related to a renal ' catastrophe,' and in the great majority of cases is a recoverable lesion.

In any case of oliguria obstruction to the urinary tract must be excluded-a plain X-ray of the abdomen can be very helpful-and if such obstruction exists, it must either be relieved or a nephrostomy be performed immediately.

Lowered blood pressure, loss of blood and 
depletion of body water or salt are prerenal factors which must be righted if possible. Renal failure entirely conditioned by prerenal factors will not persist, at any rate as far as the excretion of water is concerned, if these factors are righted. Full renal function, and the ability to concentrate the urine, may not be recovered for some weeks. Acute renal failure due to a primary disturbance in the kidney may frequently be complicated by prerenal factors, but the failure will persist despite their correction as long as the renal cause remains. A chronic renal disease may easily be tipped into failure by a prerenal factor, and if the latter is righted renal function may return to its previous level.

The treatment of oliguric renal failure is directed towards keeping a patient alive long enough for renal function to recover sufficiently to support life. Most patients dying in uraemia die of heart failure as the immediate cause. The two main contributory factors to the onset of heart failure are overloading of the circulation by increasing above normal the water content of the body, as a result of 'forcing fluids,' and the retention of potassium with abnormally high serum levels.

The main features of the management are :-

I. Strict maintenance of fluid balance. Only sufficient fluid is given to replace the water lost to the body. One litre may be taken as the amount lost in the 24 hours by way of the lungs, skin and in the faeces.

2. To reduce the accumulation of protein breakdown products a high calorie, non- or lowprotein diet is given.

3. The minimum potassium should be given in drinks and food. In particular to be avoided are any synthetic fruit drinks, which may contain large amounts of potassium.

4. Electrolyte imbalances should only be corrected if this can be done without upsetting the fluid balance. No potassium salts must be used therapeutically.

5. Infection should be prevented if possible and is an indication for routine penicillin administration. If infection is present this must be vigorously combated.

The indications for intervention in a case of anuria with either the artificial kidney or peritoneal dialysis are extremely difficult to define. Whether an ideally managed case of anuria should need dialysis is very doubtful, as it should be possible to keep any such patient alive for I4 days, by which time the large majority of recoverable lesions will have started a diuresis. Gross oedema and high serum potassium levels will only be found in cases which have not been carefully managed, and these are probably the main clinical indications for $\frac{2}{3}$ the use of any form of dialysis at the present time. $\stackrel{\mathbb{Q}}{\circ}$

In conclusion it is stressed that the majority of $c$ cases of acute renal failure with oliguria have a $\overrightarrow{\vec{D}}$ recoverable lesion. Some renal function recovery should be expected within 14 days from the $\frac{5}{0}$ onset of the failure, and correct management should keep a patient alive for at least this length of time.

\section{REFERENGES}

I. FISHBERG, A. M. (1939), 'Hypertension and Nephritis,' $\vec{\omega}$
Philadelphia.

2. O'SULLIVAN, J. V., and SPITZER, W. (1946), F. Obstet. Gynaec., 53, 158.

3. DUFF, G. L., and MORE, R. H. (1941), Amer. Y. Med. Sci., 㝋 $201,428$.

4. GIBBERD, G. F. (1936), f. Obstet. Gynaec., 43, 60.

5. CROOK, A. (1926-7), Proc. Roy. Soc. Med., 20, 1249.

6. SCRIVER, W. de M., and OERTEL, H. (r930), チ. Path. Bact., 33, 1071 .

7. GROEN, J., and LINDEBOOM, G. A. (1940), Nederl. Tydschr. Geneisk, 84, 688.

8. BYWATERS, E. G. L. (1945), Brit. Med. Bull., 694.

9. OLSON, W. H., and NECHELLS, H. (1947), Surg. Gynec. Obstet., 84, 28. 1. LONGCOPE, W. T., and LUETSCHER, J. A. (1946), F. Clin. 零

I I. KEMPNER, W. (1946), Bull. New York Acad. Med., 22, 358. ف

12. BORST, J. G. G. (1947), Nederl. Tydschr. Geneisk., 91, 2718.

13. BORST, J. G. G. (1948), Lancet, i, 824.

14. HUMPHREY, J. H., and AVERY-JONES, F. (1947), Clin, S 6, 173 .

15. KOLFF, W. J., Personal communication.

16. BULL, G. M., JOEKES, A. M., and LOWE, K., Unpublished work.

17. LATTIMER, J. K. (1945), F. Urol., 54, 312.

18. KUGEL, V. H. (1947), Amer. F. Med., 3, 188.

19. KIRK, E. (1946), Suppl. 183, Acta Med. Scand.

20. HOFF, SMITH and WINKLER (r94I), f. Clin. Invest., 20, $\stackrel{\mathbb{D}}{\varrho}$ 607.

21. FINCH, C. A., SAWYER, C. G., and FLYNN, J. M. (1946), $\overline{\bar{O}}$ Amer. F. Med., i, 337.

22. BYWATERS, E. G. L. (1944), Ұ. Amer. Med. Ass., 124, 1 103. ᄀ

23. KOLFF, W. J., and BERK, H. T. J. (1944), Acta. Med. Scand., 117, 121.

24. KOLFF, W. J. (1947), 'New Ways of Treating Uraemia,' Churchill, Londor.

25. ALWALL, N. (1947), Acta. Med. Scand., 128, 317.

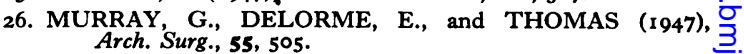

27. ALWALL, N., and NORVIT (1947), Acta. Med. Scand., Suppl. 196, 250.

28. BALASZ and ROSENAK (1934), Wien. Klin. Wchnschr., 47, Э 851 .

29. FINE, J., FRANK, H. A., and SELIGMAN, A. M. (1946), 음 f. Amer. Med. Ass., 130, 703 .

30. KOP, P. S. M. (I 948), Thesis, 'Peritoneal Dialyse,' Kampen. I

31. ODEL, H. M., and FERRIS, D. O. (1948), Proc. Mayo Clin., 三. 23, 201 .

32. SELIGMAN, A. M., FRANK, H. A., and FINE, J. (1946), م

F. Clin. Invest., 25, 211 .
33. BYWATERS, E. G. L., and JOEKES, A. M. (1948), Proc. Roy. Soc. Med., 41, 420.

34. ABESHOUSE, B. S. (1945), F. Urol., 53, 27.

35. PETERS, J. T. (1945), Ann. Intern. Med., 23, 221.

6. MUIRHEAD, E. E., et al. (1948), Blood, Special issue No IOI.

37. COLLER, F. A., CAMPBELL, K. N., and IOB, V. (1948), Ann. Surg., I28, 379.

38. LUCKE, B. (1946), Mil. Surg., 99, 37 I. 